\title{
Renal function is a determinant of subjective well-being in active seniors but not in patients with subjective memory complaints
}

\author{
Lovisa A Olsson ${ }^{1,2^{*}}$, Nils-Olof Hagnelius ${ }^{3}$ and Torbjörn K Nilsson ${ }^{4}$
}

\begin{abstract}
Background: During our whole life span, factors influencing health and functioning are accumulated. In chronic kidney disease, quality of life is adversely affected. We hypothesized that biomarkers of renal function could also be determinants of subjective well-being (SWB) in Swedish elderly subjects. SWB was assessed by the Psychological General Well-Being index (PGWB index) in two study groups: Active seniors (AS) consisted of community-dwelling elderly Swedes leading an active life $(n=389)$, and the DGM cohort $(n=300)$ consisted of subjects referred to the Memory Unit at the Department of Geriatrics for memory problems, Serum creatinine, cystatin C, and eGFR (CKD-EPI) were used as biomarkers of renal function.

Results: There were no significant differences in cystatin $C$ and eGFR values between the two cohorts: cystatin C medians 0.88 vs $0.86 \mathrm{mg} / \mathrm{L}$ and eGFR 73 vs $80 \mathrm{~mL} / \mathrm{min} / 1.73 \mathrm{~m}^{2}$ (AS vs DGM). In the AS cohort cystatin C was negatively related to PGWB index in women $\left(P<0.001, R^{2} \approx 5 \%\right)$, and the covariates age and BMI did not improve the models. The renal biomarkers were unrelated to the PGWB index in the DGM cohort. Cystatin $C$ in the AS cohort was adversely related to the PGWB subdimensions anxiety, depressed mood, positive well-being, and vitality in women, but in men only to depressed mood $\left(P<0.006 ; R^{2} \approx 6 \%\right)$. In the DGM cohort, depressed mood in men was also significantly related to cystatin $C(P=0.050)$, but not in women.
\end{abstract}

Conclusions: Renal function even within the normal range, measured by serum cystatin $C$ concentration, has significant and sex specific associations with subjective well-being and its subdimensions in healthy elderly subjects. Maintenance of good renal function in aging may be of importance in maintaining a high subjective well-being.

Keywords: Creatinine, Cystatin C, Subjective well-being, Biomarkers, Elderly, Renal function

\section{Background}

During our whole life span, factors that influence health and functioning are accumulated; these factors include genetics, environment, and individual life experience and exposures [1]. Moderate renal dysfunction is increasing worldwide [2] and has been associated with an increased risk of death from cardiovascular events and kidney failure [3-5] and a number of other clinical conditions $[6,7]$. While it is well known that in more pronounced renal dysfunction (chronic kidney disease, CKD), quality

\footnotetext{
* Correspondence: lovisa.olsson@orebroll.se

'Department of Laboratory Medicine/Clinical Chemistry, Örebro University Hospital, Södra Grev Rosengatan, 70185 Örebro, Sweden

${ }^{2}$ School of Health and Medical Science, Örebro University, Fakultetsgatan 1, 70281 Örebro, Sweden

Full list of author information is available at the end of the article
}

of life (QoL) is adversely affected [8-10] there is a relative dearth of studies addressing the possibility that CKD could also be related to Subjective Well-Being (SWB), a person's own evaluation of his or her life. Such evaluations may be judgments about the person's life as a whole or evaluations of specific dimensions of life, both positive and negative $[1,11]$. In particular, next to nothing is known about the possibility that SWB (or QoL) might be affected even by moderate renal dysfunction (MRD), perhaps even while biomarkers of renal function, used to estimate glomerular filtration (eGFR), still remain within the reference interval.

S-creatinine and S-cystatin C are commonly used as biomarkers to calculate eGFR. Among the disadvantages of C-creatinine as a GRF marker are its dependence on muscle mass, age, race and sex of the subjects [12], tubular 
secretion, drugs and dietary intake [13,14]. Cystatin $C$ is a protease inhibitor produced in nearly all human cells. Its serum concentration is independent of muscle mass and sex [12], and it has been proposed as a better biomarker of GFR than creatinine [15].

We hypothesized that a possible negative effect of kidney function on SWB could contribute substantially to the total variance in SWB in an elderly population even in the absence of CKD. The aim of this study was thus to look for possible associations between established biomarkers of renal function (S-creatinine, S-cystatin C, and eGFR) and subjective well-being in a sample of 689 Swedish elderly subjects.

\section{Methods}

\section{Subjects}

Active Seniors (AS) cohort was recruited during 2003 and 2004 by a multi-phase sampling procedure aimed at an elderly retired population living in various communities in Central Sweden. The locations for the recruitment were selected to represent a broad range of socioeconomic levels and included rural as well as urban and suburban areas. The sample consisted of 389 senior citizens and was recruited from several retired persons' organisations, which implicates that they are independent and socially active. Being retired, living independently in their own homes in addition to participation in such organisations were the sole inclusion criteria, not pre-set health criteria. We have designated them as 'Active Seniors' in contrast to elderly persons that do not engage themselves in such social activity. All were Caucasians, most of them born in the 1920's and 1930's, mean age at sampling was $74 \pm$ 5 years for both sexes and the sex ratio M/F was 127/262. Based upon the cystatin $\mathrm{C}$ values in different age groups (Figure 1), the number of AS subjects with cystatin $C$ above the upper reference limit $(1.55 \mathrm{mg} / \mathrm{L})$ was 7 women and 3 men (total prevalence $2.6 \%$ ).

A random subset of the AS cohort was assessed by the Mini Mental State Examination (MMSE) [16] and the clock drawing test (CDT) judged according to Shulman [17]. These subjects $(n=154)$ were found to be cognitively intact, defined as MMSE $\geq 28$ and CDT $\geq 4$ Neither the PGWB score nor any of the studied biomarkers differed significantly between this subgroup and the rest of the AS study group. We therefore regard the AS cohort as a cognitively intact group of elderly subjects.

Senior subjects with subjective or objective cognitive complaints (DGM cohort) were recruited from an incident case study at the University Hospital, Örebro Sweden [18]. Briefly this study population consisted of 300 consecutive patients (143 men and 157 women) who were referred to the Memory Unit at the Department of Geriatrics for diagnostic assessment and treatment of suspected cognitive problems. The inclusion period extended from

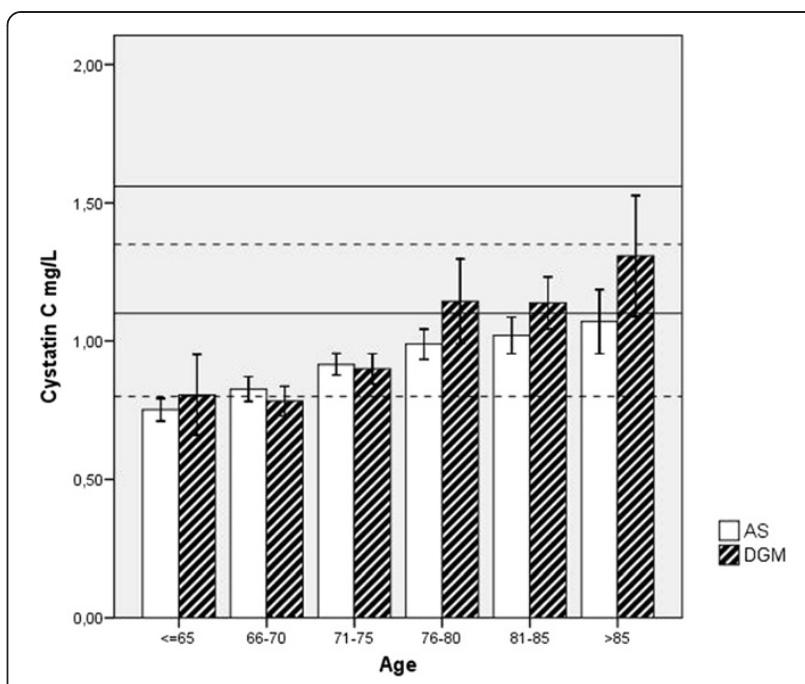

Figure 1 Cystatin $\mathrm{C}$ values in in the two study groups stratified by age in $\mathbf{5}$-year intervals. Mean values and $95 \% \mathrm{Cls}$ of the means are shown. The dotted lines show our in-house reference values for the $51-65$ year-olds $(95 \% \mathrm{Cl})$, and the continuous lines those of the 65-80 year-olds.

May 2003 to August 2007. The cognitive problems had to be mild or moderate, defined as MMSE score $\geq 10$; according to current Swedish research ethics legislation it is unethical and thus forbidden to include subjects with more severe dementia due to their reduced autonomy. Dementia diagnoses were based on DSM-IV criteria ICD-10 criteria was used to divide dementia patients into different diagnostic categories. Mixed dementia (F 00.2 according to ICD-10) was diagnosed in cases of coexistence of $\mathrm{AD}$ and a history of vascular risk factors e.g. transitory ischemic attack(s). atrial fibrillation, hypertension, diabetes mellitus, Hachinski ischemic score $\geq 6$ and CT scan showing ischemic changes. Probable AD was diagnosed in accordance with the NINCDS-ADRDA criteria. Of the 73 subjects classified as ND, 39 were MCI. Everyone in the study group completed the PGWB questionnaire without assistance during their visit at the Memory unit. Based upon the cystatin $C$ values in different age groups (Figure 1), the number of DGM subjects with cystatin $C$ above the upper reference limit $(1.55 \mathrm{mg} / \mathrm{L})$ was 12 women and 9 men (total prevalence $7 \%$ ).

All subjects gave a specific and written informed consent to the present study including genotyping and biobanking of the donated samples. The Research Ethics Committee of Örebro County Council and the Regional Ethics Review Board (Uppsala) approved the study. Height and weight (SECA digital scale, 99\% of the subjects) were measured and BMI $(\mathrm{kg} / \mathrm{m} 2)$ was calculated. The resting systolic and diastolic blood pressure was measured using an automatic oscillometric method (Dinamap model XL Critikron, Inc., Tampa, Florida.). The equipment has been validated. 


\section{Assessment of subjective well-being}

The Psychological General Well-Being (PGWB) index, accessible from MAPI Research institute, www.mapitrust.fr, was used to measure subjective well-being or distress [19]. It consists of 22 items that reflect a sense of subjective well-being and distress during the past week. The items are divided into six dimensions, anxiety, depressed mood, positive well-being, self-control, general health, and vitality; these are also combined to a global overall score of SWB. Response categories for all items were simplified to a 6-point Likert scale. A high value indicates a high level of well-being. In order to achieve this interpretation of the score-points even for the dimensions which reflect distress (depressed mood and anxiety). score-points for these items were assigned in the direction of " 6 " to " 1 " in contrast to the usual direction of " 1 " to " 6 ". The overall sum of scores gives a maximum value of 132 (best SWB) and a minimum of 22 (poorest SWB).

\section{Blood sampling and biochemical measurements}

Blood samples were taken with the subjects in the supine position, by venipuncture using vacuum tubes with gel, Becton Dickison. Serum was obtained after clotting for 30 to 60 minutes at room temperature and centrifuging at room temperature for 10 minutes at $2000 \mathrm{~g}$. All samples were stored at $-80^{\circ} \mathrm{C}$. The serum samples were analysed on a Hitachi 911 multianalyser, Roche, Mannheim, FRG. Creatinine was analysed using a enzymatic method, Crea plus, from Roche/Boehringer Mannheim FRG, and the calibrator was IDMS standardised. Albumin, IgG, IgA and IgM were analysed by immunoturbidimetry using reagents from DAKO, Copenhagen, Denmark and cystatin C by immunoparticle turbidimetry from Gentian AS, Moss, Norway. LDL and HDL cholesterol were measured by direct, homogeneous assays based on detergent treatment of the serum. N-geneous ${ }^{\mathrm{TM}}$ HDL-c and N-geneous ${ }^{\mathrm{TM}}$ LDL reagents, respectively, from Genzyme Corporation, Cambridge, MA, USA.

Estimated glomerular filtration rate (eGFR) was calculated using the equation which include both creatinine and cystatin C from the Chronic Kidney Disease Epidemiology collaboration. This equation includes both creatinine and cystatin $C$ as well as age, sex and race [20]. In the present study all participants were of European descent.

\section{Statistics}

All variables were checked for normality of distribution and collinearity before analysis. Continuous variables with a skewed distribution were transformed using natural logarithms before regression analyses were made. The Mann-Whitney rank sum test was used to compare the PGWB sum and PGWB sub-dimension between gender in the two cohorts, median and interquartile range for descriptive statistics of these variables.
A forward multiple regression was used to determine the degree to which variance in PGWB index was explained by age, $\mathrm{BMI}$, gender and, cystatin $\mathrm{C}$ or creatinin. To examine which of the subdimensions contributed to the variance in PGWB index ANCOVA analyses were done with age, BMI, and biomarkers of kidney function as covariates. All multivariate regression models were performed after stratification, since we have found profound differences between SWB in the AS and DGM cohorts [21].

Statistical analyses were performed using SPSS version 15.0 (Chicago, Illinois, USA), and PGWB Statistical significance were considered with a probability value $<0.05$.

In the AS study group, 4 subjects failed to complete the PGWB questionnaire and responses from 12 subjects failed to answer one or two questions randomly distributed among the 22 questions. The missing answers were imputed using the manual from MAPI research institute.

\section{Results}

Baseline characteristics

Baseline characteristics of the two study groups are shown in Table 1. Men in the DGM cohort were significantly younger than in the AS cohort. Within the AS cohort men had significantly higher diastolic blood pressure and serum creatinine concentrations than women. Within the DGM cohort creatinine and plasma IgA differed significantly between sexes. Serum creatinine mean concentrations also differed between women in the AS and DGM cohorts, while there was no difference between any sub-group comparison concerning cystatin $C$ mean concentrations. There was a difference in eGFR between the two study groups, and also between the sexes in the AS cohort, but the prevalence of subjects with an eGFR (KDGIO) $<60 \mathrm{~mL} / \mathrm{min} / 1.73 \mathrm{~m}^{2}$ was similar, $22 \%$, in both the AS and DGM cohorts. A cystatin C concentration $>1.1 \mathrm{mg} / \mathrm{mL}$ was found in $16 \%$ of subjects in the AS cohort and $22 \%$ in the DGM cohort.

There were group differences in SWB, assessed by the PGWB instrument, between the two cohorts, see Table 2. In the DGM cohort men had significantly higher well-being than women in all sub-dimensions but positive well-being. In the AS cohort the only sex difference was that women had a significantly lower degree of self-control. When comparing women in the AS and the DGM cohorts, DGM women had significantly lower SWB than AS women. That was also the finding comparing men in both cohorts, except for general health.

\section{Biomarkers of renal function and PGWB index}

In the AS cohort, cystatin $\mathrm{C}$ was significantly and negatively related to $\mathrm{PGWB}$ index in women, explaining $\approx 5 \%$ of the variance in SWB, as seen in Table 3. Addition of the covariates age and BMI did not substantially improve this model. In men too there was a negative correlation of 
Table 1 Baseline and laboratory characteristics of the studied 689 seniors

\begin{tabular}{|c|c|c|c|c|c|c|c|c|}
\hline \multirow{2}{*}{$\begin{array}{l}\text { Mean (SD) and } p \text {-values for } \\
\text { the sex differences are shown }\end{array}$} & \multicolumn{3}{|c|}{ Active seniors cohort } & \multicolumn{3}{|c|}{ DGM cohort } & \multirow[b]{2}{*}{$P^{\mathrm{b}}$} & \multirow[b]{2}{*}{$P^{c}$} \\
\hline & Women $n=262$ & Men $n=127$ & $P^{a}$ & Women $n=157$ & Men $n=143$ & $P^{a}$ & & \\
\hline Age. yr & $74.4(7.2)$ & $75.0(6.4)$ & NS & $73.3(10.6)$ & $72.5(9.5)$ & NS & NS & 0.028 \\
\hline Height, cm & $163(5.8)$ & $177(6.7)$ & $<0.001$ & $163(5.9)$ & $176(1.2)$ & $<0.001$ & $<0.001$ & $<0.001$ \\
\hline $\mathrm{BMl}, \mathrm{kg} / \mathrm{cm} 2$ & $26.0(4.2)$ & $26.1(3.5)$ & NS & $25.8(3.7)$ & $26.2(3.7)$ & NS & NS & NS \\
\hline systBPsitting, mm Hg & $148.9(26.1)$ & $146(22.5)$ & NS & $150(23.7)$ & $149(23.6)$ & NS & NS & NS \\
\hline diastBPsitting, mm Hg & $76.3(11.3)$ & $78.0(10.4)$ & 0.013 & $82.3(12.5)$ & $84.1(12.1)$ & NS & $<0.001$ & $<0.001$ \\
\hline S-Creatinine, umol/L & $87.4(21.5)$ & $101(16.8)$ & $<0.001$ & $78.9(36.6)$ & $97.9(58.9)$ & $<.001$ & $<0.001$ & NS \\
\hline S-Cystatin C, mg/L & $1.02(0.25)$ & $1.04(0.22)$ & NS & $0.98(0.54)$ & $1.01(0.45)$ & NS & NS & NS \\
\hline eGFR mL/min/1,73 $\mathrm{m}^{2}$ & $70.1(15.95)$ & $74.0(14.48)$ & 0.022 & $76.1(22.8)$ & $78.6(23.24)$ & NS & 0.002 & 0.049 \\
\hline hS-CRP, mg/L & $2.06(2.13)$ & $2.90(3.74)$ & NS & 3.34 (6.38) & $5.51(16.01)$ & NS & NS & NS \\
\hline P-Albumin, $g / L$ & $40.9(3.41)$ & $40.7(3.46)$ & NS & $36.5(3.30)$ & $36.9(3.22)$ & NS & $<0.001$ & $<0.001$ \\
\hline P-lgG, g/L & $11.9(2.7)$ & $12.1(2.9)$ & NS & $9.83(2.38)$ & $10.24(2.69)$ & NS & $<0.001$ & $<0.001$ \\
\hline P-lgM, g/L & $1.23(0.79)$ & 1.09 (1.50) & NS & $1.01(0.99)$ & $0.86(0.62)$ & NS & 0.035 & NS \\
\hline P-lgA, g/L & $2.37(.08)$ & $1.40(0.36)$ & 0.004 & $2.16(1.21)$ & $2.62(1.07)$ & 0.002 & NS & NS \\
\hline
\end{tabular}

cystatin $C$ with PGWB index, the $\beta$ coefficient was numerically similar to the one in women $(-10.1$ vs. -12.2$)$, and reached borderline statistical significance $(P=0.06)$. Just as in women, addition of age and BMI as covariates did not change this pattern; cystatin $C$ retained its $\beta$ value around the same numerical level $(-10.7)$, again showing borderline significance $(P=0.07)$.

In the AS cohort, serum creatinine too was, in women, significantly and negatively related to PGWB index $(P=0.02)$ but explained only $\approx 2 \%$ of its variance. Adding the covariates age and BMI increased the explanatory power of the model to $\approx 6 \%$. In men, creatinine was unrelated to PGWB index, and adding age and BMI as covariates did not improve the insignificant $R^{2}$ (Table 3 , models 4 and 5).
In contrast, in the DGM cohort neither cystatin $C$ nor creatinine were significantly related to PGWB index, and none of the extended models had any explanatory power (Table 3, lower panel).

\section{Cystatin $C$ and PGWB subdimensions}

In Table 4 , the relations of PGWB subdimensions with cystatin $\mathrm{C}$ are shown. In women in the AS cohort, cystatin $\mathrm{C}$ was significantly and adversely related to the dimensions anxiety, depressed mood, positive well-being, and vitality. In contrast, in women in the DGM cohort cystatin $C$ was unrelated to any of the PGWB subdimension.

In men, in the AS cohort there was a significantly adverse relation between cystatin $\mathrm{C}$ and depressed mood, which explained $\approx 6 \%$ of its variance $(P=0.006)$. In the

Table 2 SWB as PGWBsum and its subdimensions in the study groups active seniors and DGM

\begin{tabular}{|c|c|c|c|c|c|c|c|c|}
\hline & \multicolumn{3}{|c|}{ Active seniors cohort } & \multicolumn{3}{|c|}{ DGM cohort } & \multirow[b]{2}{*}{$P^{\mathrm{b}}$} & \multirow[b]{2}{*}{$P^{c}$} \\
\hline & Women & Men & $P^{\mathrm{a}}$ & Women & Men & $P^{\mathrm{a}}$ & & \\
\hline Anxiety & $27(24-29)$ & $27(25-29)$ & Ns & $22(20-27)$ & $25(22-28)$ & 0.005 & $<0.001$ & $<0.001$ \\
\hline Depressed mood & $17(15-18)$ & $17(15-18)$ & NS & $15(13-17)$ & $16(14-17)$ & 0.019 & $<0.001$ & $<0.001$ \\
\hline Pos.well-being & 18 (15-19) & $18(16-19)$ & NS & $15(12-18)$ & $16(13-18)$ & Ns & $<0.001$ & $<0.001$ \\
\hline Self control & $15(16-17)$ & $17(16-17)$ & 0.018 & $14(12-16)$ & $15(13-16)$ & 0.006 & $<0.001$ & $<0.001$ \\
\hline General. health & $16(14-17)$ & $16(13-17)$ & NS & $14(12-13)$ & $15(13-17)$ & 0.006 & $<0.001$ & NS \\
\hline Vitality & $19(17-21)$ & $19(17-21)$ & NS & $17(13-20$ & $18(16-20)$ & 0.016 & $<0.001$ & 0.003 \\
\hline PGWB sum & $112(101-118)$ & $113(105-118)$ & NS & 97.5 (85-109) & $104(90-115)$ & 0.001 & $<0.001$ & $<0.001$ \\
\hline
\end{tabular}

$P^{\mathrm{a}}$ Sex difference within cohort.

$P^{\mathrm{b}}$ Difference between women in the AS and DGM cohorts.

$P^{C}$ Difference between men in the AS and DGM cohorts.

Median and the interquartile range $25 \%-75 \%$ are shown. 
Table 3 ANCOVA models examining the association of the PGWB index with the covariates cystatin C, creatinine, eGFR, $B M I$, and age

\begin{tabular}{|c|c|c|c|c|c|c|c|}
\hline \multirow{2}{*}{$\begin{array}{l}\text { AS cohort } \\
\text { Model }\end{array}$} & \multirow[b]{2}{*}{ Predictor variables } & \multirow[b]{2}{*}{$\beta$} & \multicolumn{2}{|c|}{ Women } & \multirow[b]{2}{*}{$\beta$} & \multicolumn{2}{|c|}{ Men } \\
\hline & & & $\bar{P}$ & $R^{2}$ model & & $\bar{P}$ & $R^{2}$ model \\
\hline 1 & cystatin C & -12.2 & $<0.001$ & 0.048 & -10.1 & 0.061 & 0.019 \\
\hline \multirow[t]{2}{*}{2} & Age & -0.341 & 0.006 & 0.030 & -0.013 & 0.942 & -0.008 \\
\hline & BMI & 0.262 & 0.206 & & -0.315 & 0.345 & \\
\hline \multirow[t]{3}{*}{3} & Age & -0.201 & 0.125 & 0.053 & 0.119 & 0.540 & 0.009 \\
\hline & BMI & -0.167 & 0.418 & & -0.150 & 0.662 & \\
\hline & cystatin C & -9.721 & 0.008 & & -10.69 & 0.071 & \\
\hline 4 & creatinine & -10.359 & 0.017 & 0.019 & -7.592 & 0.318 & 0.00 \\
\hline \multirow[t]{3}{*}{5} & Age & -0.283 & 0.029 & 0.058 & 0.020 & 0.915 & -0.009 \\
\hline & BMI & -0.287 & 0.166 & & -0.281 & 0.406 & \\
\hline & creatinine & -8.31 & 0.058 & & -8.255 & 0.288 & \\
\hline 4 & eGFR & 0.164 & 0.002 & 0.019 & 0.128 & 0.116 & 0.009 \\
\hline \multirow[t]{3}{*}{5} & Age & -0.203 & 0.157 & 0.038 & 0.160 & 0.455 & 0.003 \\
\hline & BMI & -0.198 & 0.341 & & -0.165 & 0.633 & \\
\hline & eGFR & 0.113 & 0.070 & & 0.156 & 0.104 & \\
\hline \multicolumn{3}{|l|}{ DGM cohort } & \multicolumn{2}{|c|}{ Women } & & \multicolumn{2}{|c|}{ Men } \\
\hline Model & Predictor variables & $\beta$ & $\bar{P}$ & $R^{2}$ model & $\beta$ & $\bar{P}$ & $R^{2}$ model \\
\hline 1 & Cystatin C & 0.42 & 0.856 & -0.006 & -1.4 & 0.651 & -0.006 \\
\hline \multirow[t]{2}{*}{2} & Age & 0.045 & 0.709 & -0.009 & 0.136 & 0.366 & -0.007 \\
\hline & BMl & 0.274 & 0.429 & & 0.258 & 0.501 & \\
\hline \multirow[t]{3}{*}{3} & Age & 0.045 & 0.728 & -0.016 & 0.266 & 0.116 & 0.00 \\
\hline & BMI & 0.250 & 0.475 & & 0.332 & 0.394 & \\
\hline & cystatin C & 0.187 & 0.938 & & -3.699 & 0.289 & \\
\hline 4 & creatinine & 2.162 & 0.590 & -0.005 & 2.943 & 0.526 & -0.004 \\
\hline \multirow[t]{3}{*}{5} & Age & 0.035 & 0.774 & -0.014 & 0.115 & 0.473 & -0.013 \\
\hline & BMI & 0.271 & 0.434 & & 0.261 & 0.498 & \\
\hline & creatinine & 2.016 & 0.622 & & 1.969 & 0.691 & \\
\hline 6 & eGFR & 0.021 & 0.698 & -0.016 & -0.016 & 0.787 & 0.000 \\
\hline \multirow[t]{3}{*}{7} & Age & 0.113 & 0.457 & -0.012 & 0.279 & 0.173 & -0.005 \\
\hline & BMI & 0.274 & 0.433 & & 0,312 & 0.423 & \\
\hline & eGFR & 0.050 & 0.462 & & 0.053 & 0.514 & \\
\hline
\end{tabular}

Numbers in boldface indicate statistically significant associations.

DGM cohort too, cystatin $C$ in men was significantly and adversely correlated with depressed $\operatorname{mood}(P=0.050)$, although the variance explained was minor $(\approx 1 \%)$. In the AS cohort, there was also an adverse relation between positive well-being and cystatin $C(P=0.03)$, explaining $\approx 2.5 \%$ of that subdimension.

\section{Discussion}

The main finding was a negative correlation between SWB, assessed by the PGWB index and serum cystatin C as a biomarker of renal function, even after adjusting for age and BMI, in Active Seniors but not in subjects with subjective memory complaints (DGM cohort), two cohorts of Swedish elderly subjects with a low prevalence of chronic kidney disease (CKD) as judged from their serum cystatin $\mathrm{C}$ concentrations.

There were marked gender differences in the adverse relation between cystatin $\mathrm{C}$ and the subdimensions of SWB. In women in the AS cohort all subdimensions except self control were adversely related to cystatin C, whereas in the DGM cohort cystatin $C$ was unrelated to any SWB subdimension. (see Table 4). In contrast, in men, there was a significant adverse relation of cystatin $\mathrm{C}$ only with depressed mood, and this relation was seen both in the AS and in the DGM cohorts. Interestingly, in the AS cohort the beta factor for men was twice that 
Table 4 ANCOVA of the PGWB subdimensions

\begin{tabular}{|c|c|c|c|c|c|c|c|}
\hline \multirow{2}{*}{$\begin{array}{l}\text { Women } \\
\text { PGWB subdimension }\end{array}$} & \multirow[b]{2}{*}{ Predictor variables } & \multicolumn{3}{|c|}{ Active seniors cohort } & \multicolumn{3}{|c|}{ DGM cohort } \\
\hline & & $\bar{\beta}$ & $P$ & $R^{2}$ model & $\bar{\beta}$ & $P$ & $R^{2}$ model \\
\hline \multirow[t]{3}{*}{ Anxiety } & Age & -0.012 & 0.728 & 0.010 & 0.046 & 0.196 & -0.003 \\
\hline & BMI & 0.019 & 0.730 & & 0.071 & 0.462 & \\
\hline & cystatin C & -1.955 & 0.046 & & 0.265 & 0.692 & \\
\hline \multirow[t]{3}{*}{ Depressed mood } & Age & -0.024 & 0.260 & 0.026 & -0.029 & 0.183 & 0.001 \\
\hline & BMl & 0.002 & 0.948 & & 0.055 & 0.353 & \\
\hline & Cystatin C & -1.269 & 0.029 & & 0.085 & 0.865 & \\
\hline \multirow[t]{3}{*}{ Positive well-being } & Age & -0.039 & 0.191 & 0.031 & -0.15 & 0.566 & -0.003 \\
\hline & BMI & -0.001 & 0.975 & & 0.089 & 0.205 & \\
\hline & Cystatin C & -1.886 & 0.023 & & -0.162 & 0.738 & \\
\hline \multirow[t]{3}{*}{ Self control } & Age & -0.024 & 0.259 & 0.018 & 0.012 & 0.604 & -0.010 \\
\hline & BMI & -0.014 & 0.680 & & 0.046 & 0.461 & \\
\hline & Cystatin C & -1.019 & 0.078 & & 0.303 & 0.83 & \\
\hline \multirow[t]{3}{*}{ General health } & Age & -0.070 & 0.005 & 0.073 & 0.005 & 0.854 & -0.015 \\
\hline & BMI & -0.078 & 0.043 & & -0.054 & 0.424 & \\
\hline & Cystatin C & -1.021 & 0.133 & & 0.037 & 0.938 & \\
\hline \multirow[t]{3}{*}{ Vitality } & Age & -0.031 & 0.331 & 0.064 & 0.026 & 0.462 & -0.015 \\
\hline & BMI & -0.093 & 0.063 & & 0.043 & 0.652 & \\
\hline & Cystatin C & -2.609 & 0.003 & & -0.339 & 0.606 & \\
\hline \multicolumn{2}{|l|}{ Men } & \multicolumn{3}{|c|}{ Active seniors cohort } & \multicolumn{3}{|c|}{ DGM cohort } \\
\hline PGWB subdimension & Predictor variables & $\beta$ & $P$ & $R^{2}$ & $\beta$ & $P$ & $R^{2}$ \\
\hline \multirow[t]{3}{*}{ Anxiety } & Age & -0.033 & 0.496 & -0.015 & 0.069 & 0.122 & -0.002 \\
\hline & BMl & 0.037 & 0.670 & & 0.093 & 0.365 & \\
\hline & cystatin C & -1.420 & 0.335 & & -0.567 & 0.537 & \\
\hline \multirow[t]{3}{*}{ Depressed mood } & Age & -0.22 & 0.462 & 0.063 & 0.041 & 0.134 & 0.011 \\
\hline & BMl & -0.004 & 0.932 & & 0.038 & 0.552 & \\
\hline & Cystatin C & -2.472 & 0.006 & & -1.122 & 0.050 & \\
\hline \multirow[t]{3}{*}{ Positive well-being } & Age & -0.014 & 0.728 & 0.025 & 0.025 & 0.478 & -0.12 \\
\hline & BMI & 0.015 & 0.828 & & 0.070 & 0.392 & \\
\hline & Cystatin C & -2.649 & 0.031 & & 0.154 & 0.833 & \\
\hline \multirow[t]{3}{*}{ Self control } & Age & 0.072 & 0.009 & 0.032 & 0.060 & 0.032 & 0.032 \\
\hline & BMl & 0.027 & 0.572 & & 0.073 & 0.256 & \\
\hline & Cystatin C & -1.237 & 0.135 & & -0.944 & 0.103 & \\
\hline \multirow[t]{3}{*}{ General health } & Age & 0.009 & 0.844 & 0.029 & 0.028 & 0.357 & -0.006 \\
\hline & BMI & -0.145 & 0.059 & & -0.012 & 0.869 & \\
\hline & Cystatin C & -1.654 & 0.209 & & -0.871 & 0.171 & \\
\hline \multirow[t]{3}{*}{ Vitality } & Age & 0.034 & 0.480 & -0.007 & 0.042 & 0.240 & -0.009 \\
\hline & BMI & -0.050 & 0.554 & & 0.069 & 0.398 & \\
\hline & Cystatin C & -1.560 & 0.283 & & -0.349 & 0.635 & \\
\hline
\end{tabular}

Numbers in boldface indicate statistically significant associations.

of women (-2.5 vs. -1.3$)$ somehow reflecting a higher sensitivity to depressed mood in men, further supported by the fact that this adverse relation was significant even in males in the DGM cohort (beta value -1.1).
To the best of our knowledge, the above findings regarding the adverse relations between a biomarker of renal function and important aspects of subjective wellbeing in subjects with renal function within the normal 
range have not been reported before. Previous studies about QoL have mostly been conducted in patients with CKD, end state renal disease (ESRD), or on hemodialysis, with QoL as outcome variable, not SWB. Health Related Quality of Life (HRQoL) has been found to be reduced in proportion to the severity of CKD [22,23]. Our findings thus extend the scope of renal function twofold, both to another dimension besides QoL, namely SWB, and to the importance of minor reduction in renal function as a determinant of SWB.

In the Health, Aging and Composition study, cystatin $\mathrm{C}$ was not associated with depression at baseline but participants having cystatin $C$ higher than $1.25 \mathrm{mg} / \mathrm{L}$ had an increased risk to develop diagnosed depression [24]. In the prospective Cardiovascular Health Study, cystatin $\mathrm{C}$ was associated with depression among participants without CKD at baseline but this was a borderline association after adjusting for both demographic and clinical measures [25]. We regard these studies as consistent with our finding of an adverse relation between cystatin $\mathrm{C}$ and depressed mood in both sexes in the AS cohort, and among men even in the DGM cohort.

SWB includes a person's evaluation of his or hers life, both positive and negative feelings as well as perceptions of one's situation. In our model cystatin $\mathrm{C}$ explained 6\% of the SWB variance which is regarded as clinically relevant. SWB has been associated with longevity [26-28]. Chida and Steptoe showed in their meta-analysis that high SWB was associated with reduced mortality in healthy populations [29]. They also concluded that a high SWB appeared to be protective against increased mortality, even in CKD patients. We speculate that the association between SWB and renal function could provide a missing link between SWB, longevity, and mortality $[3,4,30]$ even in subjects without CKD.

SWB differs between the sexes [31,32] as also shown in our cohorts. Therefore it is of special relevance that a number of renal functions also differ between the sexes, further supporting a link between renal function and SWB. [33,34]. We contend that, based on the documented links between renal function, SWB, and mortality, monitoring of cystatin $\mathrm{C}$ in the elderly may help identifying subjects in need of more proactive treatment to prevent further deterioration of renal function. Successful intervention might impact both SWB and mortality positively in the elderly. Prospective studies will be necessary to address this possibility.

There are some limitations in our study. SWB is a function of many variables such as socioeconomic status, marital status, physical health, life expectations [35-37], and in this study we were not able to control for all of these factors. However, reverse causation (low PGWB scores due to poor SES and/or marital status causing a reduced GFR) seems unlikely as confounder, since establishment of marital status and SES regularly take place early in life whereas reduced GFR develops gradually in the aging subject (Figure 1), and it thus appears unlikely that a reduced GFR would significantly affect marital status and SES. Personality and genetic variation may also contribute substantially [38]. These factors should be included in future studies.

\section{Conclusion}

Renal function even within the normal range, assessed by serum cystatin $C$ concentration, has significant and sex specific associations with SWB and its subdimensions. Maintenance of good renal function in aging may therefore be of importance not only in preventing somatic deterioration in old age but also in maintaining a good subjective well-being.

\section{Competing interests}

The authors declare that they have no competing interests.

\section{Authors' contributions}

$\mathrm{LO}, \mathrm{TN}$ and $\mathrm{NOH}$ participated in the design of the study. $\mathrm{LO}$ and $\mathrm{NOH}$ recruited the study populations and analyzed the data. All authors drafted, read and approved the final manuscript.

\section{Acknowledgements}

The Research Committee of Örebro County Council and Nyckelfonden Örebro are gratefully acknowledged for financial support. The sponsors had no role in study design; in the collection, analysis and interpretation of data; in the writing of the report; or in the decision to submit the article for publication.

\section{Author details}

${ }^{1}$ Department of Laboratory Medicine/Clinical Chemistry, Örebro University Hospital, Södra Grev Rosengatan, 70185 Örebro, Sweden. ${ }^{2}$ School of Health and Medical Science, Örebro University, Fakultetsgatan 1, 70281 Örebro, Sweden. ${ }^{3}$ Department of Geriatrics, Örebro University Hospital, Södra Grev Rosengatan, 70185 Örebro, Sweden. ${ }^{4}$ Department of Medical Biosciences, Clinical Chemistry, Umeå University, Byggnad 6M, 90185 Umeå, Sweden.

Received: 19 June 2014 Accepted: 8 September 2014

Published: 15 September 2014

\section{References}

1. Inui TS: The need for an integrated biopsychosocial approach to research on successful aging. Ann Intern Med 2003, 139:391-394.

2. Stenvinkel P: Chronic kidney disease: a public health priority and harbinger of premature cardiovascular disease. J Intern Med 2010, 268:456-467.

3. Shlipak MG, Sarnak MJ, Katz R, Fried LF, Seliger SL, Newman AB, Siscovick DS, Stehman-Breen C: Cystatin C and the risk of death and cardiovascular events among elderly persons. N Engl J Med 2005, 352:2049-2060.

4. Larsson A, Helmersson J, Hansson LO, Basu S: Increased serum cystatin C is associated with increased mortality in elderly men. Scand J Clin Lab Invest 2005, 65:301-305.

5. Sarnak MJ, Levey AS, Schoolwerth AC, Coresh J, Culleton B, Hamm LL, McCullough PA, Kasiske BL, Kelepouris E, Klag MJ, Parfrey P, Pfeffer M, Raij L, Spinosa DJ, Wilson PW: Kidney disease as a risk factor for development of cardiovascular disease: a statement from the American Heart Association Councils on Kidney in Cardiovascular Disease, high blood pressure research, clinical cardiology, and epidemiology and prevention. Circulation 2003, 108:2154-2169.

6. Wasén E, Isoaho R, Mattila K, Vahlberg T, Kivela SL, Irjala K: Serum cystatin C in the aged: relationships with health status. Am J Kidney Dis 2003, 42:36-43.

7. Go AS, Chertow GM, Fan D, McCulloch CE, Hsu CY: Chronic kidney disease and the risks of death, cardiovascular events, and hospitalization. $N$ Engl J Med 2004, 351:1296-1305. 
8. Finkelstein FO, Wuerth D, Finkelstein $\mathrm{SH}$ : Health related quality of life and the CKD patient: challenges for the nephrology community. Kidney Int 2009, 76:946-952.

9. Kalantar-Zadeh K, Unruh M: Health related quality of life in patients with chronic kidney disease. Int Urol Nephrol 2005, 37:367-378.

10. Mapes DL, Lopes AA, Satayathum S, McCullough KP, Goodkin DA, Locatelli F, Fukuhara S, Young EW, Kurokawa K, Saito A, Bommer J, Wolfe RA, Held PJ, Port FK: Health-related quality of life as a predictor of mortality and hospitalization: the Dialysis Outcomes and Practice Patterns Study (DOPPS). Kidney Int 2003, 64:339-349.

11. Bradburn NM: The Structure of Psychological Well-Being. Chicago: Aldine Pub; 1969.

12. Vinge $E$, Lindergard $B$, Nilsson-Ehle $P$, Grubb A: Relationships among serum cystatin C, serum creatinine, lean tissue mass and glomerular filtration rate in healthy adults. Scand J Clin Lab Invest 1999, 59:587-592.

13. Levey AS: Measurement of renal function in chronic renal disease. Kidney Int 1990, 38:167-184.

14. Berglund F, Killander J, Pompeius R: Effect of trimethoprim-sulfamethoxazole on the renal excretion of creatinine in man. J Urol 1975, 114:802-808.

15. Grubb A, Bjork J, Lindstrom V, Sterner G, Bondesson P, Nyman U: A cystatin C-based formula without anthropometric variables estimates glomerular filtration rate better than creatinine clearance using the Cockcroft-Gault formula. Scand J Clin Lab Invest 2005, 65:153-162.

16. Folstein MF, Folstein SE, McHugh PR: Mini-mental state. A practical method for grading the cognitive state of patients for the clinician. J Psychiatr Res 1975, 12:189-198.

17. Shulman Kl: Clock-drawing: is it the ideal cognitive screening test? Int J Geriatr Psychiatry 2000, 15:548-561.

18. Hagnelius NO, Wahlund LO, Nilsson TK: CSF/serum folate gradient: physiology and determinants with special reference to dementia. Dement Geriatr Cogn Disord 2008, 25:516-523.

19. Dupuy HJ: The Psychological General Well-Being (PGWB) Index. In Assessment of Quality of Life in Clinical Trials of Cardiovascular Therapies. Edited by Wenger N, Mattson M, Furberg C, Elinson J. New York: Le Jaca Pub; 1984:170-183.

20. Inker LA, Schmid CH, Tighiouart H, Eckfeldt JH, Feldman HI, Greene T, Kusek JW, Manzi J, Van Lente F, Zhang YL, Coresh J, Levey AS: Estimating glomerular filtration rate from serum creatinine and cystatin C. N Engl J Med 2012, 367:20-29.

21. Olsson LA, Hagnelius NO, Olsson H, Nilsson TK: Subjective well-being in Swedish active seniors or seniors with cognitive complaints and its relation to commonly available biomarkers. Arch Gerontol Geriatr 2013, 56:303-308.

22. Pagels A, Soderkvist B, Medin C, Hylander B, Heiwe S: Health-related quality of life in different stages of chronic kidney disease and at initiation of dialysis treatment. Health Qual Life Outcomes 2012, 10:71

23. Mujais SK, Story K, Brouillette J, Takano T, Soroka S, Franek C, Mendelssohn D, Finkelstein FO: Health-related quality of life in CKD Patients: correlates and evolution over time. Clin J Am Soc Nephrol 2009, 4:1293-1301.

24. Minev E, Unruh M, Shlipak MG, Simsonick E, Yaffe K, Leak TS, Newman AB, Fried LF, Health ABCS: Association of cystatin $C$ and depression in healthy elders: the health, aging and body composition study. Nephron Clin Pract 2010, 116:c241-c246.

25. Kop WJ, Seliger SL, Fink JC, Katz R, Odden MC, Fried LF, Rifkin DE, Sarnak MJ, Gottdiener JS: Longitudinal association of depressive symptoms with rapid kidney function decline and adverse clinical renal disease outcomes. Clin J Am Soc Nephrol 2011, 6:834-844.

26. Wiest M, Schuz B, Webster N, Wurm S: Subjective well-being and mortality revisited: differential effects of cognitive and emotional facets of well-being on mortality. Health Psychol 2011, 30:728-735.

27. Sadler ME, Miller CJ, Christensen K, McGue M: Subjective wellbeing and longevity: a co-twin control study. Twin Res Hum Genet 2011, 14:249-256.

28. Nilsson G, Ohrvik J, Lonnberg I, Hedberg P: Low Psychological General Well-Being (PGWB) is associated with deteriorated 10-year survival in men but not in women among the elderly. Arch Gerontol Geriatr 2011, 52:167-171.

29. Chida Y, Steptoe A: Positive psychological well-being and mortality: a quantitative review of prospective observational studies. Psychosom Med 2008, 70:741-756

30. Okura T, Jotoku M, Irita J, Enomoto D, Nagao T, Desilva VR, Yamane S, Pei Z, Kojima S, Hamano Y, Mashiba S, Kurata M, Miyoshi K, Higaki J: Association between cystatin $C$ and inflammation in patients with essential hypertension. Clin Exp Nephrol 2010, 14:584-588.

31. Sonnenberg CM, Beekman ATF, Deeg DJH, van Tilburg W: Sex differences in late-life depression. Acta Psychiatr Scand 2000, 101:286-292.

32. Gallant M, Chauret N, Claveau D, Day S, Deschenes D, Dube D, Huang Z, Lacombe $P$, Laliberte F, Levesque JF, Liu S, Macdonald D, Mancini J, Masson P, Mastracchio A, Nicholson D, Nicoll-Griffith DA, Perrier H, Salem M, Styhler A, Young RN, Girard Y: Design, synthesis, and biological evaluation of 8-biarylquinolines: a novel class of PDE4 inhibitors. Bioorg Med Chem Lett 2008, 18:1407-1412.

33. Maric C: Sex, diabetes and the kidney. Am J Physiol Ren Physiol 2009, 296:F680-F688.

34. Sabolić I, Asif A, Budach W, Wanke C, Bahn A, Burckhardt G: Gender differences in kidney function. Pflugers Arch 2007, 455:397-429.

35. Diener E, Chan MY: Happy people live longer: subjective well-being contributes to health and longevity. App/ Psychol 2011, 3:1-43.

36. Ni Mhaolain AM, Gallagher D, H OC, Chin AV, Bruce I, Hamilton F, Teehee E, Coen R, Coakley D, Cunningham C, Walsh JB, Lawlor BA: Subjective well-being amongst community-dwelling elders: what determines satisfaction with life? Findings from the Dublin Healthy Aging Study. Int Psychogeriatr 2012, 24:316-323.

37. Grossi E, Sacco P, Blessi G, Cerutti R: The impact of culture on the individual subjective well-being of the Italian population: an exploratory study. Appl Res Qual Life 2011, 6:387-410.

38. Röysamb E, Tambs K, Reichborn-Kjennerud T, Neale MC, Harris JR: Happiness and health: environmental and genetic contributions to the relationship between subjective well-being, perceived health, and somatic illness. $J$ Pers Soc Psychol 2003, 85:1136-1146.

doi:10.1186/1756-0500-7-647

Cite this article as: Olsson et al:: Renal function is a determinant of subjective well-being in active seniors but not in patients with subjective memory complaints. BMC Research Notes 2014 7:647.

\section{Submit your next manuscript to BioMed Central and take full advantage of:}

- Convenient online submission

- Thorough peer review

- No space constraints or color figure charges

- Immediate publication on acceptance

- Inclusion in PubMed, CAS, Scopus and Google Scholar

- Research which is freely available for redistribution 